\title{
REFLEXÕES BIBLIOTECONÔMICAS NO SERVIÇO DE REFERÊNCIA EM ARQUIVOS PERMANENTES
}

\author{
ADRIANNE BRAGATO* \\ ENDERSON MEDEIROS
}

\begin{abstract}
RESUMO
$\mathrm{O}$ artigo discute a aplicabilidade da teoria biblioteconômica do serviço de referência ao contexto dos arquivos permanentes. Faz, também, uma revisão de literatura, tanto nas teorias do serviço de referência quanto nas que tratam sobre o arquivo permanente e o serviço de referência que é prestado neste tipo de arquivo. Aborda, ainda, a questão da necessidade da existência de um profissional especializado no serviço de referência para atuação nos arquivos permanentes como forma de garantir o desenvolvimento do serviço de referência e melhorar a qualidade no atendimento de demandas informacionais dos usuários. Trabalha, ainda, questões complementares, mas imprescindíveis para a estruturação do serviço de referência em arquivos permanentes, como o estudo de usuário e sua formação. Por fim, mostra como a adaptação e aplicação da teoria sobre serviço de referência, desenvolvida pela Biblioteconomia, pode contribuir para a melhoria do atendimento aos usuários que frequentam arquivos permanentes e aponta ações práticas e objetivas que devem ser tomadas para que as teorias e práticas do serviço de referência sejam adotadas nos arquivos permanentes com sucesso.
\end{abstract}

PALAVRAS-CHAVE: Arquivo Permanente. Serviço de referência. Arquivista de referência. Estudo de usuário. Formação de usuários.

\section{BIBLIOTECHONOMIC REFLECTIONS IN THE REFERENCE SERVICE IN PERMANENT ARCHIVES}

\begin{abstract}
The article deals with the applicability of library service theory of reference to the context of permanent archives, reviewing literature both in reference service theories and in theories dealing with the
\end{abstract}

*Analista em Biblioteconomia no Ministério Público do Estado de Goiás. Graduada em Biblioteconomia pela Universidade Federal de Goiás (UFG) (2008). Especialista em Gestão da Informação e Tecnologias da Informação pela Faculdade Sul Americana (FASAM) (2017) drica_bragato@yahoo.com.br

Graduação em Biblioteconomia pela Universidade Federal de Goiás (2006). Especialização em História Cultural pela Universidade Federal de Goiás (2010). Mestrado em História pela Universidade Federal de Goiás (2016). enderbass@hotmail.com 
permanent archive and the reference service that is provided in this service. file type. It also addresses the need for a professional specialized in the reference service to work in permanent files as a way of guaranteeing the development of the referral service in permanent files and improving the quality in meeting the users' informational demands. It also works on complementary, but essential issues for structuring the referral service in permanent files such as the study of user and user training. Finally, it shows how the adaptation and application of reference service theory developed by librarianship can contribute to the improvement of the attendance to users who attend permanent archives and points out practical and objective actions that must be taken so that the theories and practices of the reference service adopted in permanent files.

KEYWORDS: Permanent Archive. Reference service. Reference archivist. User study. User training. Librarianship

\section{INTRODUÇÃO}

O termo e o conceito de serviço de referência são citados, conhecidos e trabalhados no contexto das bibliotecas. Entretanto, percebe-se que este termo/conceito ainda é pouco utilizado e trabalhado no contexto das instituições arquivísticas.

As bibliotecas e os arquivos, tratados como unidades de informação, possuem como objetivo principal e comum garantir a disponibilização e o acesso de informações e documentos de maneira tratada e ordenada. Isso permite, assim, o futuro uso destas informações e documentos para satisfazer necessidades informacionais de seus usuários. Partindo destas semelhanças em suas naturezas, percebe-se a necessidade comum do desenvolvimento de um serviço de referência, que tenha embasamento teórico em sua execução. Entende-se, neste aspecto, que o serviço de referência engloba tanto a assistência pessoal, que o profissional da informação presta aos seus usuários, como todas as atividades de divulgação, facilitação de acesso e disponibilização de dados executadas por uma unidade de informação. Desta forma, ao investigar como as atividades de referência têm sido descritas e apresentadas na literatura arquivística, é pertinente verificar a adequação e as possíveis contribuições teóricas advindas da biblioteconomia e desenvolvidas nos arquivos permanentes.

Desse modo, a pesquisa procura apresentar contribuições que exploram e alargam a ideia do serviço de referência ainda pouco abordado no contexto arquivístico. A problemática que impulsiona o desenvolvimento desta investigação busca responder à seguinte 
questão: Como a teoria do serviço de referência desenvolvida e aplicada no contexto das bibliotecas pode contribuir para melhorar o atendimento aos usuários nos arquivos permanentes?

O objetivo se dá em caracterizar as contribuições da teoria biblioteconômica sobre o serviço de referência, as atividades de referência e o atendimento ao usuário nos arquivos permanentes. Para o desenvolvimento deste estudo, optou-se pela metodologia da pesquisa bibliográfica, levantando, na literatura da área da Biblioteconomia, os autores e as teorias que tratam sobre o serviço de referência.

Nesta fase, a obra utilizada foi o livro: A prática do serviço de referência, de Denis Grogan (2001). A escolha dessa obra se deu por ser um trabalho de grande fôlego sobre o tema e uma das principais referências na área.Levantaram-se, também, bibliografias que tratam sobre o arquivo permanente, visando compreender seu funcionamento, seus objetivos, seus usuários e os usos práticos que são feitos dos documentos de valor permanente. Neste momento, foram consultadas as seguintes obras: Arquivos Modernos de T. R. Schellenberg (2006), Arquivos Permanentes da autora Heloísa Liberalli Bellotto (2006) e um artigo de Priscila Lopes Menezes (2012), que trata sobre a atividade de difusão nos arquivos permanentes, almejando verificar a adequação do desenvolvimento do serviço de referência dentro da atividade de difusão em arquivos permanentes.

Por fim, foram levantadas as bibliografias que tratavam do funcionamento do serviço de referência em arquivos. Entre os autores consultados, estão: Pedro Penteado (1995); José Luís Hernándes Luis (2016); Diego Navarro Bonilla (2001); Huilig Feng (2017); Robert W. Tissing (1984); Janice E. Ruth (1988); Ciaran B. Trace e Carlos J. Ovalle (2012); Jorge Santa Anna e Suelen de Oliveira Campos (2016); Kathyanne Samara Paulino Vasconcelos, Maria de Fátima Teixeira Veras e Kátia Isabelle de B. Melo de Souza (2011), Glaucia Aparecida Vaz e Carlos Alberto Ávila Araújo (2015) e Fernando Alves Gama e Edberto Ferneda (2010).A partir das leituras das bibliografias das áreas da Biblioteconomia e da Arquivologia, procurou-se estabelecer relações entre a teoria biblioteconômica do serviço de referência e sua adaptação e aplicação à realidade dos arquivos. Observou-se, também, as características específicas dos documentos de arquivos permanentes, de seus usuários e as especificidades que são próprias das unidades de informação arquivísticas. 


\section{SERVIÇO DE REFERÊNCIA}

A origem do serviço de referência é difícil de ser claramente datada e estabelecida, mas Santa Anna e Campos (2016) acreditam que este serviço tenha surgido nas primeiras relações sociais estabelecidas entre o ser humano, no momento em que se precisou de "consolidar práticas de acolhimento" (2016, p. 72). Assim, as práticas voltadas à recepção de pessoas em um determinado negócio ou estabelecimento, oferecem informações necessárias para o uso, serviço ou produto. Percebe-se que o serviço de referência tem relação íntima com atividades de atendimento a usuários ou clientes e outros tipos de serviço de prestação de informações sobre produtos, serviços e empresas. Desta forma, pode-se dizer que, praticamente todos os tipos de negócios possuem, dentro de sua gama de atividades, algum tipo de serviço, geralmente caracterizado como atendimento ao cliente ou balcão de informações, que possui uma semelhança com o serviço de referência prestado nas bibliotecas e com outras unidades de informação.

Para Figueiredo (1992 apud GAMA; FERNEDA, 2010) o serviço de referência começa a ser citado e estudado no final do século XIX. A partir deste momento, ele começa a ser bastante estudado e desenvolvido pela Biblioteconomia. Grogan (2001, p. 24) acrescenta dados sobre a origem do serviço de referência, atribuindo sua origem nas bibliotecas às discussões levantadas pelo bibliotecário Samuel Swett Green, com a publicação do "primeiro trabalho sobre o serviço de referência"em 1876.

A priori, para se definir um conceito para serviço de referência, é preciso atentar para o fato de que este pode ser conceituado tanto no sentido geral como no sentido específico. Robert. e. Balay (apud GROGAN, 2001, p. 2) define serviço de referência no sentido geral como "tudo que os departamentos de referência executam" e Samuel Rosthein (apud GROGAN, 2001, p. 2) define serviço de referência, no sentido estrito, como a assistência pessoal prestada pelo profissional da informação aos usuários em busca de informação. Santa Anna e Campos (2016, p. 72) ressaltam que o serviço de referência "pode ser visualizado como um conjunto de ações de acolhimento realizadas em uma relação entre humanos".

É importante acrescentar que o serviço de referência é uma das formas de mediação da informação que pode ser realizada 
entre o profissional da informação e o usuário da informação. Almeida Júnior $(2008$, p. 3) conceitua mediação como:

toda ação de interferência - realizada pelo profissional da informação - direta ou indireta; consciente ou inconsciente; singular ou plural; individual ou coletiva; que satisfaça, plena ou parcialmente, uma necessidade informacional.

Pode-se concluir, então, que até mesmo as atividades de organização de um acervo e de elaboração de instrumentos de pesquisa são formas de mediação que o profissional da informação executa. Este trabalho visa tornar o acesso aos documentos de sua unidade de informação mais compreensível, fácil e eficiente para o usuário.

Kenneth Whiaker (apud GROGAN, 2001, p. 8) afirma que a finalidade do serviço de referência é "permitir que as informações fluam eficientemente entre as fontes de informações e quem precisa de informações".

Um importante autor que trata do serviço de referência na Biblioteconomia é Denis Grogan, que apresentou, em seu livro, A prática do serviço de referência (2001), uma teoria bem estruturada a respeito do serviço de referência em seu sentido estrito. Dessa forma, o atendimento pessoal que o profissional da informação presta ao usuário, quando este chega em uma unidade de informação, em busca de um conhecimento específico; de uma resposta para o seu problema ou necessidade de informação.

Grogan (2001) aborda, de forma detalhada, o processo de referência, definindo-o como as atividades que envolvem o usuário durante a realização do serviço de referência. Assim, o processo de referência se inicia no momento em que uma questão é apresentada ao profissional da informação pelo usuário e termina quando se chega ao consenso entre profissional e usuário, ou seja, quando a questão é respondida de maneira satisfatória. Grogan (2001) lembra, também, que o processo de referência remonta ao momento em que o usuário reconhece a existência de um problema e identifica que, para a sua resolução, é necessário buscar informações.

Assim, Grogan (2001) elenca oito passos ou etapas, em ordem lógica, que configuram o processo de referência, sendo eles:

1) Problema;

2) Necessidade de informação;

3) A questão inicial; 
4) A questão negociada;

5) A estratégia de busca;

6) O processo de busca;

7) A resposta;

8) A solução.

O problema advém de algum acontecimento na vida do indivíduo, podendo ter origem interna (psicológica) ou externa (contexto social). Se, para a resolução do problema, o indivíduo julgar ser necessária alguma informação, logo este indivíduo formula uma questão inicial, que utiliza para tentar localizar a informação de que necessita para resolver o problema. Muitas vezes, o sujeito consegue, por si mesmo, depois de formular uma questão inicial, localizar a informação de que necessita, sem auxílio profissional. Entretanto, outras vezes, não possui a competência necessária para buscar por si só a informação de que necessita, e assim, busca um profissional da informação em uma unidade de informação, apresentando a questão inicial ao profissional do serviço de referência. A partir deste ponto, surge a questão negociada e o profissional da informação, que, por meio de uma entrevista de referência, tenta extrair mais dados do usuário em busca de detalhes e de uma melhor compreensão do problema, bem como da necessidade de informação do usuário.

Neste momento, o profissional da informação já faz comparações da questão apresentada pelo usuário com a forma como o acervo está organizado. Isto visa definir os termos que utilizará para fazer uma busca nos instrumentos de pesquisa ou a maneira mais eficiente de localizar o documento que contém a informação necessária para sanar a necessidade informacional do usuário. Depois de negociar a questão do usuário, o profissional da informação elabora uma estratégia de busca, para localizar a informação necessária. Esta estratégia inclui determinar: o acervo que será consultado, as partes do acervo e em que ordem.

Desta forma, o profissional da informação estabelece como será feita a comparação entre a questão do usuário e o acervo ou instrumentos de pesquisa que a instituição possui e seleciona as categorias de fontes que podem conter a informação, bem como uma fonte específica ou documento que possa contê-la. O próximo passo é o processo de busca, que consiste na pesquisa propriamente dita, em que é aconselhável que o usuário acompanhe este processo, pois, assim, ele oferece uma reação imediata ao material apresentado pelo profissional da informação. É importante, 
ainda, para uma busca eficaz, que a estratégia seja flexível para comportar alterações durante sua execução, conforme as reações apresentadas pelo usuário. Após, o profissional da informação apresenta a resposta (resultado da busca) ao usuário e o da informação e o usuário verificarão se a resposta apresentada satisfaz adequadamente a necessidade de informação do usuário. Caso satisfaça, chega-se, finalmente chega-se à solução do problema e, assim, se dá por encerrado o processo de referência.

Grogan (2001) ainda aborda outro ponto interessante em sua teoria, referindo-se às questões de referência e dividindo-as em:

a) Questões de auxílio limitado - estas são questões de resposta específica, fáceis de perceber quando a réplica foi ou não localizada, por exemplo, consultas de caráter administrativo e de orientação espacial; consultas sobre autor/título e consulta de localização de fatos;

b) Questões de auxílio prolongado - estas são questões abertas a respeito de assuntos, em que, muitas vezes, é necessário que o profissional da informação execute uma busca exaustiva, apresentando muitas fontes e, outras vezes, uma única fonte responde à questão. Por exemplo: a busca por documentos que tratem de um assunto específico.

Todos estes aspectos levantados sobre o serviço de referência: processo, entrevista e questões de referência podem ser desenvolvidos e utilizados em qualquer tipo de unidade de informação, inclusive nos arquivos permanentes.

Ruth (1988) salienta que o extenso corpo da literatura biblioteconômica em serviço e entrevista de referência pode ser utilizado para apresentar técnicas de comunicação para arquivistas. Isso pode ajudá-los bastante na melhoria do atendimento de seus usuários. Entretanto, para se utilizar as teorias do serviço de referência, desenvolvidas pela Biblioteconomia no contexto dos arquivos permanentes, faz-se necessário conhecer, a concepção e o funcionamento deste tipo de arquivo, bem como seus objetivos, os tipos de documentos e as informações que armazenam, assim como os tipos de usuários e demandas informativas que recebem. A partir deste conhecimento, pode-se refletir a necessidade de adaptações da teoria e a promoção de associações que possam enriquecer o estudo do serviço de referência no contexto dos arquivos permanentes. 


\section{ARQUIVOS PERMANENTES}

$\mathrm{O}$ arquivo permanente, também denominado arquivo histórico, é definido pelo Dicionário de brasileiro de terminologia arquivística, elaborado pelo Arquivo Nacional, (2005, p.34) como "conjunto de documentos preservados em caráter definitivo em função de seu valor". Os documentos de um arquivo permanente são caracterizados por já terem perdido o seu valor primário que, no caso, corresponde à razão pela qual o documento foi criado. São documentos elaborados e recebidos por uma determinada instituição (pública ou privada) ou pessoa física, no exercício de suas atividades, meios e fins, podendo ser utilizados com objetivos administrativos, jurídicos e/ou fiscais. Desta forma, os documentos de arquivo permanente possuem como característica principal o seu valor secundário, que se configura como importâncias além dos motivos pelos quais o documento foi criado. Pode ser utilizado para fins de testemunho, prova e informação de ações, atividades, direitos e contextos culturais e sociais, possuindo, assim, valor informativo, histórico e cultural.

Cabe lembrar que os arquivos permanentes não servem apenas à administração, pois guardam documentos importantes para a memória institucional. Mas também servem a toda população, pois são fontes para pesquisas de diversas naturezas, inclusive para a comprovação de direitos.

Assim, a finalidade de um arquivo permanente é conservar os documentos com valores secundários e garantir o acesso destes documentos a todos indivíduos que se interessem pelas informações neles contidas. Para se atingir tal finalidade, cabe ao arquivo permanente executar atividades de recolhimento; arranjo; descrição e difusão.

Para Bellotto (2006, p. 29):

O arranjo (que nada mais é do que a classificação no âmbito dos arquivos permanentes) é comandado pela estrutura e pelo funcionamento da administração. $O$ arranjo pode ser considerado a acomodação que se faz à classificação efetuada anteriormente, depois das baixas sofridas em decorrência da avaliação.

Após, organizar os fundos e arranjar as séries documentais é o momento de se iniciar a atividade de descrição. É através da descrição dos documentos em que são construídos os instrumentos de pesquisa, essenciais para que o usuário do arquivo tenha acesso 
às informações contidas nos documentos, pois é através dos instrumentos de pesquisa que se torna possível a recuperação da informação. Assim, a descrição faz um elo entre os documentos de arquivo e o usuário. Bellotto (2006. p. 29-30) ressalta que:

A descrição é ditada pelos interesses da pesquisa, sem que se percam com a proveniência e a funcionalidade do documento em sua origem. A coexistência dessa dualidade é a única forma - e bem sabem os arquivistas e os historiadores experientes - de os arquivos servirem adequadamente a ambas as áreas (administração e história) sem deformações prejudiciais à fidedignidade dos dados e, consequentemente, à veracidade das informações extraídas dos documentos.

Depois que o acervo de um arquivo permanente é devidamente organizado em fundos; de ser feito o arranjo; e de ser feita toda sua descrição, desdobrando-se estas atividades na criação de instrumentos de pesquisa dos mais variados tipos (guias, catálogos, inventários, índices, etc.); cabe ao arquivo permanente executar sua função fundamental. Esta finalidade é de difundir seu acervo e torná-lo acessível e disponível aos usuários que se interessem por ele.

Menezes (2012, p. 52) afirma que uma das funções arquivísticas fundamentais é a difusão, que auxilia "para que se cumpra o acesso à informação, esta deve promover a divulgação da instituição, das atividades arquivísticas e do acervo documental". 2011, p. 5)

Para Bellotto (2006 apud VASCONCELOS, VERAS e SOUZA,

"a difusão do acervo visa levar o arquivo para fora de seus limites estruturais, ou seja, divulgá-lo tanto no órgão, como fora deste, promovendo ao arquivo atingir um campo de abrangência cada vez maior".

Menezes (2012, p. 55), faz, ainda, uma colocação que indica que é exatamente dentro da atividade de difusão que os arquivos permanentes podem desenvolver um serviço de referência estruturado, pois:

as atividades de difusão são a porta de entrada para mostrar o que existe referente ao uso e à acessibilidade dos recursos disponíveis nas instituições arquivísticas.

Dessa maneira, uso e acessibilidade são exatamente o que o serviço de referência deve promover. 


\section{SERVIÇO DE REFERÊNCIA EM ARQUIVOS PERMANENTES}

No contexto dos arquivos, pode-se encontrar um conceito de serviço de referência, no Dicionário de Terminologia Arquivística, (2005, p. 153), que o conceitua como:

conjunto de atividades destinadas a orientar o usuário quanto aos documentos relativos ao tema de seu interesse, aos instrumentos de pesquisa disponíveis e às condições de acesso e de reprodução.

Penteado (1995, p. 19) apresenta um conceito de serviço de referência retirado do Dicionário de Terminologia Arquivística publicado em Portugal:

O serviço do arquivo que tem como função orientar os utilizadores, informando-os sobre a documentação existente, sua comunicabilidade, acessibilidade e formas de acesso, e facultando-lhes os respectivos instrumentos de descrição documental. (ALVES, 1993, apud PENTEADO, 1995, p. 19-20)

Entretanto, o autor afirma que este conceito, embora aceitável, é bastante restritivo e conservador. A mesma conceituação pode ser feita para serviço de referência em arquivo, apresentado pelo Dicionário de Terminologia Arquivística, publicado no Brasil.Para este trabalho, o serviço de referência em arquivos, em seu sentido estrito, é toda a assistência pessoal de acolhimento e orientação prestada pelo arquivista de referência ao usuário. É importante ressaltar que, no sentido geral, as atividades realizadas no arquivo, que contribuem para o acesso efetivo da informação e dos documentos aos usuários são consideradas ferramentas para o serviço de referência, inclusive os padrões de descrição arquivística e os instrumentos de pesquisa. Percebe-se, assim, que o serviço de referência é bastante amplo, em seu sentido geral, e abarca atividades de facilitação de acesso à informação, divulgação do acervo e do arquivo, bem como atividades voltadas para instrução, orientação e educação de usuário. Além disso, abrange as atividades de pesquisa para identificação de perfil e comportamento de usuários e os usos que são feitos das informações e documentos do arquivo pelos que as consultam.

\subsection{O serviço de referência na literatura arquivística}

Penteado (1995) ressalta que a preocupação com serviço de referência em arquivos é recente, pois o termo em si era praticamente inexistente na literatura de arquivologia. Penteado 
(1995) salienta, ainda, que, ao contrário da realidade arquivística, o termo "reference work" já vinha sendo usado por bibliotecários desde 1871.

Navarro Bonilla (2001) ressalta que, ao se observar a literatura científica das áreas da Biblioteconomia e da Arquivologia, constata-se um contraste entre a atenção dada ao serviço de referência no âmbito das bibliotecas e o interesse praticamente nulo sobre o assunto no âmbito dos arquivos. O autor aponta, ainda, que este contraste de atenção dado ao serviço de referência em bibliotecas e arquivos é também colocado em evidência no âmbito norte-americano, apesar de associações profissionais considerarem o serviço como uma das atividades prioritárias no âmbito das atividades arquivísticas.

Penteado (1995, p. 23) afirma ainda que foi só na década de 80 que se começou a colocar:

a importância do serviço de referência em arquivos em pé de igualdade com áreas tradicionalmente dominantes, como sejam a organização de fundos ou a sua preservação.

Penteado (1995) aponta também que é nesta época que começam a surgir obras e manuais de arquivística que apontam a atividade de referência como uma das funções mais importantes nos arquivos.

Ao refletir sobre a literatura brasileirana área da arquivologia, nota-se que pouco se tem publicado a respeito do serviço de referência em arquivos. Isso pode ser configurado como uma falha da área, que é apontada por Santa Anna e Campos (2016), principalmente devido ao fato da mudança de paradigma que se deu na Arquivologia contemporânea, denominada Arquivística pós-custodial, em que o foco deixou de ser a preservação do acervo e passou a ser o acesso dos usuários. Esta nova visão teórica da arquivística tem levado estudiosos da área a pensar questões como: a) os usuários de arquivos; b) a facilitação ao acesso aos arquivos; c) a divulgação dos arquivos à população; d) o uso dos arquivos; e) os meios de tornar os arquivos mais acessíveis para diversos tipos de usuários.

Constatou-seque, diferentemente do âmbito de publicações nacionais, na literatura internacional encontra-se um maior desenvolvimento teórico e um maior número de publicações e reflexões sobre o serviço de referência em arquivos.

$\mathrm{Na}$ literatura arquivística nacional encontra-se, incipiente o debate, com poucas publicações sobre o tema. O relato de Anna 
e Campos (2016), é um dos poucos estudos que apresentam os resultados de uma pesquisa, cujo objetivo foi analisar como o serviço de referência é realizado em um arquivo de uma empresa privada na área da construção civil. Por meio de uma entrevista com a responsável pelo arquivo, Anna e Campos (2016) constatam que, apesar dos esforços da profissional entrevistada em consolidar práticas de mediação da informação por meio de comunicação entre profissional e usuário, ainda não se podia perceber a utilização de técnicas e metodologias que configurassem e consolidassem a prática efetiva e sistematizada de um serviço de referência voltado às necessidades dos usuários. Pode-se inferir que, talvez, esta situação seja reflexo do desconhecimento por parte dos profissionais de arquivo em relação a teorias que trabalham com as técnicas e os conceitos voltados para o serviço de referência e o atendimento ao usuário.

\subsection{0 arquivista de referência}

Considerando a inferência de que há pouco conhecimento por parte dos arquivistas brasileiros sobre teorias e práticas do serviço de referência, pode-se sugerir que uma maneira de modificar este cenário seria desenvolver um serviço de referência devidamente estruturado por uma especialização do profissional de arquivo. Assim, ter-se-ia um arquivista de referência, tal como foi identificado nas teorias e práticas biblioteconômicas a figura de um bibliotecário especializado no serviço de referência, conforme cita Silva (2005). É preciso, ainda, caracterizar uma especialização no desenvolvimento de estudos, reflexões e práticas de atividades do serviço de referência, voltadas para os arquivos permanentes.

Navarro Bonilla (2001) cita, em seu artigo, alguns autores como Munn, Rios e Carolyn Heald, que identificaram em suas pesquisas que há, ainda, uma conotação negativa dos profissionais de referência no âmbito dos arquivos. Isso porque os arquivistas de referência eram vistos como intrusos, pois permanecia o pensamento de que estes não possuíam a característica de "espírito de serviço público" e muitos ainda consideram o serviço de referência uma atividade secundária no âmbito das atividades realizadas dentro dos arquivos, ou um "desvio do dever principal" de organizar e preservar documentos. Esta realidade precisa e pode ser mudada, trabalhando-se a especialização dos arquivistas em serviço de referência.

No decorrer da pesquisa, foram identificados, na literatura biblioteconômica e arquivística, autores como Grogan (2001) e Silva 
(2005) da Biblioteconomia e,que apontam características técnicas e pessoais que definem um perfil para profissionais de informação que lidam com serviço de referência. Entre estes, destacou-se Silva (2005, p. 33), que caracteriza o profissional de referência como aquele que "mantêm contato mais próximo dos usuários de uma unidade de informação". Sendo assim, o profissional de referência é um mediador entre o acervo e o usuário. Silva (2005) identifica este profissional como orientador, educador e consultor em pesquisas.

Silva (2005) traz ainda as características e habilidades interpessoais necessárias ao profissional de referência. Entre elas: o hábito de leitura e atualização dos conhecimentos de forma constante; a habilidade de buscar informações, utilizando diversas mídias, ou seja, conhecimento para utilizar os recursos de tecnologia da informação disponíveis; o conhecimento sobre o acervo e as fontes de pesquisa, sendo importante saber sobre a existência dos mesmos, como manusear, como encontrar as informações desejadas nas fontes, além de ensinar ao usuário como utilizar e localizar as informações nas fontes disponíveis; a habilidade de comunicação, se expressando com facilidade; a promoção e o incentivo da cultura.

Já Hernándes Luis (2016), autor que trabalha o serviço de referência no âmbito dos arquivos,levanta características necessárias ao profissional de referência em arquivo, citadas por diversos autores, elaborando um perfil de recursos humanos para o serviço de referência em arquivos. Dentre as características, habilidades e conhecimentos levantados pelo autor estão: a) o conhecimento sobre o sistema de arquivos e sobre os acervos que o arquivo conserva; as noções de legislação referentes ao acesso à informação, ao patrimônio cultural e à propriedade intelectual; b) a experiência do profissional de atuação em outras áreas de atividades desenvolvidas no arquivo; c) os conhecimentos sobre o uso de instrumentos de pesquisa; d) a capacidade de utilizar as novas tecnologias da informação; e) os conhecimentos iniciais sobre metodologias de pesquisa histórica e de outras disciplinas humanísticas; f) a experiência com o atendimento ao público.

Grogan (2001) identifica as características desejadas para um profissional de referência, separando-as em competência profissional e pessoal. Dentro das características de competência profissional, o autor cita: a intimidade com as fontes de referência; o domínio das técnicas de buscas informatizadas; uma vasta cultura geral; o conhecimento de outras línguas e a capacidade de bem interagir com a tecnologia. Já dentre as características 
de competência pessoal, o autor se refere à: simpatia, à criatividade, à confiança, à imaginação, à adaptabilidade, à iniciativa, à diligência, à paciência, à humildade, à devoção ao serviço ao entusiasmo.

Para Penteado (1995, p. 33), que esmiuçou a questão do serviço de referência nos arquivos, as características fundamentais que se espera de um arquivista nesta área são:

a) contribuir para a selecção e desenvolvimento das fontes de informação do serviço;

b) manter as fontes de informação devidamente organizadas, em bom estado de conservação e proceder à sua divulgação;

c) atender, orientar e participar na formação de utilizadores;

d) efectuar pesquisa documentais, manuais e/ou informatizadas, dentro do âmbito de suas atividades;

e) participar na redacção de guias e outros instrumentos de descrição temáticos e especializados, compilar listagens de bibliografia e de referências de arquivo para apoio às questões mais frequentes;

f) manter ficheiros das informações prestadas aos utilizadores;

g) participar em atividades especiais, como sejam, encontros sobre a documentação de arquivos a sua utilização, mostras de documentos relevantes para o processo de referência, etc;

h) fornecer relatórios da sua atividade e outros dados que possam ajudar a avaliar a vitalidade do serviço.

Partindo destas características e/ou habilidades pessoais e técnicas necessárias para ser um bom profissional de referência, mais as funções atribuídas a este profissional, pode-se organizar e desenvolver um programa de qualificação ${ }^{1}$ ou mesmo, capacitação

\footnotetext{
${ }^{1}$ Durante a elaboração deste artigo realizou-se uma pesquisa sucinta na internet. Primeiro consultou-se no site do CONARQ quais universidades brasileiras oferecem o curso de Arquivologia. Depois foram analisadas as grades curriculares destes cursos com o objetivo de identificar a existência de disciplinas voltadas para o serviço de referência em Graduações de Arquivologia. Foram identificadas 16 universidades que oferecem concurso de Arquivologia (UFSM; UFF; UNIRIO; UNB; UNB; UFBA; UEL; UFES; UFRGS; UNESP/Marília; UEPB; FURG; UFMG; UFPB; UFAM; UFPA), destas universidades apenas duas oferecem disciplinas voltadas para o serviço de referência no curso de Arquivologia, dentre elas: a Universidade Federal Fluminense que oferece a disciplina Serviço de Referência e Informação no $3^{\circ}$ período do curso e a Universidade Federal de Santa Maria que oferece a disciplina Referência e Difusão em Arquivos no $6^{\circ}$ período do curso de Arquivologia. Tais dados demonstram uma deficiência nos currículos das universidades Brasileiras que oferecem o curso de Arquivologia, pois a maioria das universidades que oferecem o curso de Arquivologia
} 
voltada, especificamente, para o serviço de referência em arquivos permanentes. Isso contribuiria tanto para promover maior alcance dos conhecimentos das teorias e práticas do serviço de referência no contexto dos arquivos, fomentando reflexões e produções científicas sobre o tema, como também para a melhoria da qualidade da atuação profissional, e, consequentemente, do aprimoramento do atendimento prestado aos usuários de arquivos permanentes.

Silva (2005, p. 40) sintetiza a principal ideia do serviço de referência em unidades de informação, afirmando que a razão desta atividade é "estar voltada essencialmente para as pessoas, sendo que a vocação natural para ouvir e orientar, deve ser a estrutura de todo o processo de referência." Sendo as pessoas a razão para o funcionamento de um serviço de referência em uma unidade de informação, torna-se indispensável tratar sobre quem são estes sujeitos que utilizam informações e documentos de arquivos permanentes.

\subsection{O ususário no contexto do serviço de referência em arquivos permanentes}

Penteado (1995, p. 23) afirma que, no serviço de informação em arquivos permanentes, "o elemento mais importante é o utilizador", ou seja, o usuário. Isto pois o serviço de referência deve ser elaborado e organizado a partir da caracterização do usuário do arquivo permanente. Esta caracterização só pode ser conseguida com a implementação de estudos de usuários em arquivos permanentes.

Vaz e Araújo (2015) apontam que a discussão sobre usuários de arquivos começa na década de 1960. No entanto, estes mesmos autores ressaltam que foi apenas a partir de 1980, devido ao delineamento de linhas de pesquisa voltadas para o acesso aos documentos, por meio da eliminação de barreiras, que realmente houve uma verdadeira preocupação com a questão dos usuários nos arquivos. É neste contexto, que há uma mudança no paradigma da Arquivologia, passando-se de uma Arquivologia voltada para a custódia e preservação do acervo, para uma Arquivologia voltada para o acesso à informação. Vaz e Araújo (2015) salientam, também, que, no contexto atual, não há sentido na custódia se não

no Brasil não apresenta em sua grade curricular nenhuma disciplina voltada a qualificação e capacitação do profissional para exercer o serviço de referência. 
houver a garantia do acesso. Jardim e Fonseca (2004 apud Vaz; ARAÚJO, 2015) sugerem que é necessário um movimento para além da arquivística pós-custodial, buscando-se um arquivo direcionado para os usuários.

Usuário é definido pelo Dicionário brasileiro de terminologia arquivística (2015, p. 169) como "pessoa física ou jurídica que consulta arquivos". Bellotto (2006) elenca os tipos de usuários que fazem uso dos arquivos permanentes, sendo eles:

a) o administrador (aquele que necessita dos documentos para embasar o processo decisório);

b) o cidadão (interessado em testemunhos que possam comprovar seus direitos ou interessado em dados juridicamente validados ou a procura de cultura geral, de entretenimento e de conhecimento); e

c) o pesquisador (que busca os documentos visando analisar comportamento e eventos passados).

Gama e Ferneda (2010, p. 152) acrescentam que "os usuários de arquivo são divididos em duas classes, que estão diretamente ligadas ao valor primário ou secundário do documento". Desta forma, é importante observar que o comportamento informacional de cada tipo de usuário seja diferenciado e, portanto, é necessário que haja uma preocupação por parte do arquivista de referência em identificar estas condutas e as necessidades específicas de cada categoria de usuário, podendo, desta forma, adotar formas de atendimento diferenciadas na hora de executar o serviço de referência. O administrador, por exemplo, possui a compreensão da estrutura administrativa, na qual está baseada a organização dos documentos do arquivo. Por outro lado, os pesquisadores e o cidadão comum dificilmente conheceram tal estrutura. Bellotto (2006, p. 29) levanta esta questão ao dizer que "não sendo a estrutura e o funcionamento da administração do conhecimento de profissionais de história, eles necessitam destes instrumentos de pesquisa mediadores". Muitas vezes, além dos instrumentos de pesquisa como mediadores, é necessária a mediação pessoal do arquivista de referência para localizar as informações buscadas no acervo.

Ruth (1988) apresenta dados que levam à conclusão de que os arquivistas reconhecem a importância do estudo de usuário, mas ainda se mostram inseguros para elaborar e implementar este tipo de estudo. A autora afirma que os arquivistas devem aprender quem são seus usuários, como eles realizam suas pesquisas e como comunicam aos usuários informações sobre o serviço de referência. 
É importante salientar que, com o advento das novas tecnologias, está cada vez mais comum e necessário que as unidades de informação atuem fora de seus muros, mantendo sites, redes sociais, catálogos e instrumentos de pesquisa on-line, além de outras ferramentas tecnológicas que garantam acesso e visibilidade dos acervos e serviços das unidades de informação sem barreiras geográficas. A internet e as ferramentas tecnológicas podem ser instrumentos para auxiliar, inclusive, na realização de estudos de usuário, podendo-se disponibilizar, no site do arquivo permanente, formulários para que o usuário preencha, dando mais detalhes sobre necessidades informacionais e características pessoais.

Além de caracterizar os usuários do arquivo permanente, por meio dos estudos de usuário, para se estruturar um serviço de referência é necessário conhecer os usos que estes usuários fazem da informação orgânica disponível no acervo do arquivo permanente. Os usos que são feitos dos documentos e das informações disponíveis nos arquivos permanentes podem ser levantados em estudos de uso e usuário semelhantes aos realizados nas bibliotecas. Buscou-se, com isto, se levantar que tipo de informação é utilizada, de que forma e com qual finalidade.

Sobre os possíveis usos das informações e documentos disponíveis nos arquivos permanentes, Schellenberg (2006, p. 159) afirma que os arquivos permanentes são fontes de informação para:

[...] todas as atividades do governo, sendo úteis a uma grande variedades de estudos fundamentais para todos os direitos cívicos do indivíduo e para muitas questões de equidade entre os indivíduos. Importantes na regulamentação das próprias atividades do governo, são únicos e apresem-se como corpo de documentos que refletem as funções e a estrutura dos órgãos de governo.

Gama e Ferneda (2010) apontam como possíveis usos da informação orgânica, encontrada nos arquivos permanentes: a comprovação de direitos, o desenvolvimento de pesquisas e a aquisição de conhecimentos culturais. Percebe-se que os usuários que fazem uso dos arquivos permanentes são de tipos diversos e que os usos feitos dos documentos e informações disponíveis nestes arquivos também são diversificados e variados. Estas características dos usuários e dos usos das informações disponíveis em arquivos permanentes devem ser levadas em consideração ao se pensar na estruturação de um serviço de referência para arquivos permanentes. Por este motivo, nunca se deve perder de vista 
que o usuário é o indivíduo para quem se faz toda a organização do acervo arquivístico. Os documentos são higienizados, organizados, preservados e disponibilizados, visando ao uso e à consulta do usuário, buscando, assim, satisfazer sua necessidade informacional.

Assim como conhecer quem é o usuário do arquivo permanente é extremamente necessário ao se estruturar um serviço de referência, educar, instruir, treinar ou capacitar o usuário também é uma necessidade apontada por muitos autores. Hernandez Luis (2016, p. 115) salienta, ainda, que os arquivos estão atrasados na atividade de formação de usuários, se comparados às bibliotecas. O autor complementa que "para implantar um programa de formação de usuários é necessário identificar as características dos usuários".

Costa (2011) ressalta que muitos usuários de arquivo têm dificuldades de utilizar os instrumentos de pesquisa. Essa adversidade poderia ser minimizada com treinamentos de usuário ou com auxílio de um arquivista de referência.

Navarro Bonilla (2001) aponta a educação ou a formação de usuário como essencial para um serviço de referência adequado. Ele salienta a necessidade de instruir os usuários quanto aos princípios que regem a organização arquivística dos documentos, entre eles: a) mostrar os mecanismos da produção documental e seu contexto; b) ajudar o usuário a perceber a globalidade e a unidade do arquivo, bem como suas potencialidades, como fonte de informação para pesquisas diversas.

Nesta atividade de formação de usuários, mais uma vez o arquivo permanente pode se valer das tecnologias da informação e da internet para facilitar a acessibilidade da educação do usuário. Diversas bibliotecas já utilizam as ferramentas de educação a distância para ofertar cursos de capacitação de usuário, o que pode ser feito nos arquivos permanentes. Os arquivos permanentes podem, ainda, utilizar o site da instituição para disponibilizar manuais e cartilhas aos usuários, onde se apresenta os produtos e serviços da instituição e se explica como ter acesso aos mesmos. Silva (2005, p. 35) cita alguns meios empregados por bibliotecários de referência para educação de usuários on-line, que podem ser utilizados também pelos arquivos permanentes, sendo eles:

instruções gerais disponíveis na apresentação de cada recurso, helps disponíveis para responder as questões dos usuários ou até mesmo listas das questões mais comuns (FAQ-Frenquently Asked Questions) e tutorias on-line. 
Conhecer os usuários e os usos que são realizados das informações e dos documentos do arquivo permanente é essencial para se estruturar um serviço de referência. Uma das atividades que deve ser desenvolvida no serviço de referência dos arquivos permanentes é a formação ou capacitação de usuários, assim como é feito nas bibliotecas.

Em um primeiro contato do usuário com a instituição arquivística, o arquivista de referência deve buscar levantar informações sobre a experiência que o usuário possui com pesquisas a fontes primárias em arquivos e, a partir daí, delimitar o tipo de instrução ou capacitação a que o usuário precisa ser submetido. É importante lembrar, que ao capacitar o usuário de arquivos permanentes, o arquivista investe tempo nesta tarefa, mas também economiza tempo futuramente. Isso porque, a necessidade de assistência pessoal de um usuário capacitado será menor do que de um usuário que chega ao arquivo sem conhecimento algum do funcionamento, da lógica de organização e do manuseio de instrumentos de pesquisa do arquivo permanente.

\subsection{Estruturando o serviço de referência em arquivos permanentes, com base nas contribuições da literatura biblioteconômica}

$\mathrm{Na}$ realidade dos arquivos permanentes, percebe-se uma necessidade de auxílio individual para a localização de informações e de documentos ainda maior do que na realidade das bibliotecas. Nos arquivos permanentes, grande parcela dos usuários possui pouco conhecimento a respeito das possíveis lógicas de organização de arquivo, que orientam o acesso aos acervos. Além disso, é notório que muitos usuários de arquivo têm dificuldades no uso dos instrumentos de pesquisa dos arquivos. Navarro Bonilla (2001) comenta que estudos desenvolvidos sobre a satisfação dos usuários com os instrumentos de pesquisa dos arquivos permanentes mostram que estes sentem dificuldades no seu uso e percebem a necessidade de instrução e auxílio pessoal para executar essa tarefa. Provavelmente, esse fato ocorra porque existe um distanciamento da população em geral em relação ao uso do arquivo, seja ele público ou privado.

Há de se notar que, geralmente, o cidadão possui um contato, mesmo que mínimo, com a biblioteca durante sua vida escolar, mas raramente existe este contato com arquivos. Isso só aumenta a distânciada população em geral com a realidade dos arquivos, 
tornando ainda mais necessário pensar no desenvolvimento de um serviço de referência bem estruturado para orientar e auxiliar o usuário na hora de utilizar o arquivo permanente, ou mesmo, um arquivo público como fonte de informação.

Tissing (1984) comenta esta realidade, afirmando que os usuários de biblioteca podem se familiarizar com seu ambiente, catálogo, organização do acervo e classificação adotada em poucos minutos. Os usuários de arquivo, por sua vez, demoram mais tempo para se familiarizar com as buscas e os instrumentos de pesquisa dos arquivos permanentes. Tissing (1984) atribui esta realidade ao fato de que os arquivos permanentes não possuem uma classificação universal, e as áreas de armazenamento de acervo dos arquivos têm seu acesso restrito para garantir a segurança do acervo e evitar a manipulação incorreta dos documentos, bem como assegurar a integridade do arranjo.

É imprescindível a existência de instrumentos de pesquisa e de um arquivista de referência que possa fazer essa mediação ou tradução da organização do acervo baseado nos princípios arquivísticos (geralmente desconhecidos pelo usuário) e da questão apresentada pelo usuário como demanda de assunto. Isso porque, o usuário que entra em um arquivo, geralmente apresenta uma questão que se traduz como levantamento de documentos ou informações sobre um determinado assunto, e o acervo do arquivo permanente é organizado em fundos, de acordo com o princípio da proveniência.

Navarro Bonilla (2001) afirma, ainda, que os objetivos dos serviços de referência nos arquivos se assemelham ao de referência nas bibliotecas, sendo estes: a) tornar acessível a documentação custodiada pelo arquivo; b) orientar o usuário sobre os serviços ofertados; e c) servir como elo entre a riqueza e a complexidade documental e as inquietudes derivadas e surgidas no transcurso de uma investigação com fontes de arquivo.

Para estruturação de um serviço de referência arquivístico baseado nas teorias e práticas biblioteconômicas, é essencial que se dê atenção especial ao processo de referência e mais especificamente à entrevista de referência, como se pode observar na teoria de Grogan (2001). Ruth (1988) afirma que a entrevista de referência é a chave para um bom serviço de referência. Navarro Bonilla (2001), por sua vez, descreve os tipos de informações que o arquivista de referência deve extrair do usuário durante a entrevista de referência, entre elas: a origem que motivou a demanda de documentos, a finalidade, o tema concreto, e a competência 
do usuário para manejar os documentos de arquivos. Estas informações ajudam a determinar o tipo de usuário que está sendo atendido, o assunto buscado, bem como o conhecimento do usuário sobre a estrutura arquivística e os instrumentos de busca.

Tissing (1984) apresenta como resultado de sua pesquisa um guia básico padronizado para ser utilizado em qualquer entrevista de referência realizada em qualquer tipo de arquivo permanente. Apesar de não ser uma referência nova, o guia apresentado por Tissing (1984) pode ser perfeitamente utilizado nos dias de hoje e pode inclusive ser utilizado para capacitar arquivistas de referência e servir de guia de orientação no momento de realizar a entrevista de referência. O material é bem detalhado e contém 13 tópicos de atenção.

Primeiro deve-se identificar se o tipo de pesquisa que o usuário pretende realizar no arquivo pode ser respondida pelos materiais disponíveis na instituição. Caso os documentos disponíveis na instituição não possam responder à questão do usuário, deve-se indicar ao usuário outra instituição onde sua questão possa ser respondida. Caso o arquivo possua material capaz de atender à demanda do usuário, o arquivista de referência deve fornecer um formulário em que deva preencher identificando-se, apresentando informações sobre o tema de sua pesquisa e dando ou não autorização para que o arquivo compartilhe o seu contato e os dados referentes ao assunto de sua investigação com outros pesquisadores que se interessem sobre o mesmo assunto.

Em seguida, deve-se tratar da emissão do cartão de usuário do arquivo, dando as explicações pertinentes sobre sua validade. Deve-se, ainda, informar ao usuário sobre os dias e horários de funcionamento do arquivo e questioná-lo sobre a sua experiência em pesquisas em outros arquivos. Caso o usuário não tenha experiência prévia na pesquisa em arquivos, o arquivista deve apresentar ao usuário informações como: a) a natureza do acervo do arquivo; b) algumas terminologias empregadas; e c) a lógica do arranjo e das descrições dos documentos. Mas, se o pesquisador já efetuou pesquisa em outros arquivos, o arquivista tem apenas que comentar sobre o arranjo e a descrição dos documentos neste acervo específico. Depois, o arquivista deve explicar ao pesquisador sobre as regras e procedimentos para o uso da sala de consulta aos documentos e explicar os tipos de equipamentos que podem ser usados na sala de consulta, como, por exemplo, gravadores, câmeras, etc. Além disso, deixa claro se o arquivo oferece acesso a terminais de computador, microfilmes, fotocópias, bem como os procedimentos para uso destes equipamentos. 
O próximo passo é explicar ao usuário sobre os tipos de instrumentos de pesquisa disponíveis no arquivo, bem como a forma correta de uso destes instrumentos. Depois, o arquivista deve apresentar a descrição da planta do arquivo, indicando as áreas, como: sala de consulta, existência de banheiros e bebedouros, áreas para lanches e restaurantes, etc. Então, ele deve explicar ao usuário os formulários para solicitação de documentos e os prazos para sua disponibilização, caso existam. E, por fim, o arquivista deve solicitar uma cópia do resultado da pesquisa final do usuário para acrescentar aos registros do arquivo permanente, bem como explicar o motivo da existência da entrevista de referência e abrir um espaço para que o usuário apresente suas dúvidas e questionamentos, e deixar claro que está à disposição para responder qualquer dúvida futura.

Ruth (1988) trata sobre a linguagem corporal durante a entrevista de referência, um ponto que Grogan (2001) também aborda na teoria de serviço de referência de bibliotecas. Ambos autores salientam que o profissional de referência deve tomar cuidado com a postura corporal, pois ela pode sugerir interesse ou desinteresse pelo tópico de pesquisa do usuário. Outro ponto que Ruth (1988) aborda que vai ao encontro do pensamento de Grogan (2001) é referente à necessidade de se fazer questões abertas ao usuário no momento da entrevista de referência. Essas questões mantêm o canal de comunicação aberto, incentivando o usuário a falar livremente sobre o tema de sua pesquisa, o que contribui para que o profissional de referência identifique exatamente o tipo de informação de que o usuário necessita.

Silva (2005, p. 33) faz uma consideração interessante sobre a atuação do profissional de referência, indicando que este:

[...] não deve direcionar os seus serviços somente para o atendimento e interação direta com o usuário, mas também através de atividades que antecipem a demanda de informações, orientem o usuário na utilização dos recurso, e dissemine os recurso de informação disponíveis [...].

Outra atividade importante de ser realizada no serviço de referência em arquivos é o registro das questões de referência apresentadas, atividade já realizada com frequência nos serviços de referência das bibliotecas. No contexto dos arquivos permanentes, este registro possibilita que o arquivista prepare instrumentos de pesquisas ou catálogos específicos sobre assuntos buscados 
com frequência. Isto facilita a atividade de referência, tornando o atendimento ao usuário mais rápido e eficiente.

Penteado (1995, p. 35) identifica, assim como Grogan (2001) identificou em sua teoria na área da biblioteconomia, os tipos de questões que podem ser apresentadas ao serviço de referência em um arquivo permanente, sendo elas:

a) questões que procuram averiguar qual a documentação que permite abordar e resolver um assunto ou problema de base;

b) questões que procuram definir concretamente quais os fundos, séries ou documentos importantes para uma pesquisa;

c) questões que se resumem à identificação de um dado preciso (factos, biografias, topônimos, etc.);

d) questões relativas à procura de uma obra ou de uma produção de um autor, em texto manuscrito ou impresso.

Compreende-se assim, que o processo de referência nos arquivos pode utilizar a mesma estrutura teórica e prática apresentada por Grogan (2001). Destaca-se, inclusive, que muitos autores que pesquisam sobre serviço de referência em arquivos permanentes, como se pode constatar pelas comparações apresentadas, abordam aspectos semelhantes aos tratados pelo autor. Deste modo, pode-se entender que as oito ${ }^{2}$ etapas do processo de referência apresentadas por Grogan (2001) são procedimentos que podem ser utilizados para estruturar o processo de referência nos arquivos permanentes, devendo-se efetuar algumas adaptações que direcionem à prática do serviço de referência para a realidade dos arquivos.

No campo das adaptações,é preciso levar em conta as semelhanças existentes na atividade de referência realizada em bibliotecas e arquivos, para identificar práticas e teorias que podem ser aproveitadas. Mas também é preciso identificar com clareza as diferenças para trabalhar, de maneira distinta, e refletir sobre possíveis teorias e práticas, bem como efetuar ligações entre estas semelhanças e diferenças.

Penteado (1995, p. 27) aponta alguns instrumentos de trabalho do serviço de referência em arquivos permanentes, sendo eles:

a) os instrumentos de descrição documental dos fundos e coleções;

b) as bases de dados automatizadas;

2 1) problema; 2) necessidade de informação; 3) questão inicial; 4) questão negociada; 5) estratégia de busca; 6 ) processo de busca; 7) resposta; e 8) solução. 
c) a bibliografia e outras fontes de referência; e

d) os ficheiros especializados e dossiers temáticos elaborados pelo serviço.

Percebe-se grande semelhança entre os instrumentos de trabalho de referência, citados por Penteado (1995), e os instrumentos de trabalho de referência utilizados em bibliotecas: catálogos, bases de dados automatizadas; bibliografias e outras fontes de referência e registros, produzidos pelo próprio serviço de referência. Observa-se que, embora não muito trabalhado no contexto dos arquivos permanentes, muitas bibliografias e obras de referência devem estar à disposição, tanto do arquivista de referência, quanto do próprio usuário, assim como acontece na realidade das bibliotecas. É preciso identificar fontes e obras que possam ajudar o arquivista de referência na localização e identificação das informações solicitadas pelos usuários. Essas fontes devem estar sempre a mão, ou seja, precisam fazer parte dos instrumentos de referência ou, até mesmo, do acervo do arquivo permanente.

Navarro Bonilla (2001) faz outra aproximação do serviço de referência praticado nas bibliotecas com o serviço de referência realizado nos arquivos permanentes. Isso ocorre quando cita produtos de serviço de referência, geralmente desenvolvidos em bibliotecas que podem ser desenvolvidos nos arquivos permanentes, como: arquivos de referência rápida; circulares e boletins; visitas a arquivos de forma anônima para ter ideias de produtos e serviços; e criação de serviços de alerta e difusão seletiva da informação. Estas iniciativas de elaboração de produtos e serviços beneficiariam os usuários de arquivos permanentes, garantindo acesso mais eficiente e rápido à informação necessária.

De modo geral, apesar de não haver um acúmulo significativo de literatura e reflexão sobre o serviço de referência em arquivos na arquivologia brasileira, é notório que a literatura arquivística internacional tem despertado interesse nesta temática. Isso ocorre, principalmente, devido à mudança de paradigma na teoria arquivística, passando de uma arquivologia preocupada com a custódia, para uma arquivologia preocupada com 0 acesso às informações. Como citado por muitos autores referenciados, a arquivologia ainda não desenvolveu práticas e teorias do serviço de referência no mesmo nível que a Biblioteconomia desenvolveu esta temática. É partindo destes pressupostos que algumas atitudes práticas podem ser tomadas para a efetivação de um serviço 
de referência estruturado com base na teoria biblioteconômica de Grogan (2001) e de outros autores citados.

\section{CONSIDERAÇÕES FINAIS}

Sendo a Biblioteconomia pioneira nas tratativas sobre o serviço de referência, é relevante apontar algumas contribuições que podem ser extraídas das teorias e práticasna estruturação de um serviço de referência em arquivos permanentes, como, por exemplo:

a) especialização e caracterização de vaga para arquivista de referência - profissional especialista e capacitado para o desempenho de suas funções -, assim como se encontra nas bibliotecas de grande porte, arquivos de grande porte também devem possuir um profissional da informação capacitado para exclusivamente planejar e executar atividades de referência;

b) qualificação e capacitação adequada do arquivista de referência, é preciso que este profissional conheça as teorias e práticas do serviço de referência e que tenha um perfil adequado para lidar com o público, atender bem e conhecer muito bem a organização do acervo, os instrumentos de pesquisa existentes, os serviços oferecidos pelo arquivo e ter conhecimentos de outras instituições arquivísticas ou centros de documentação que possam possuir a informação solicitada pelo usuário, caso a informação desejada não esteja disponível no arquivo em que atua;

c) sistematização de estudos de usuários - é necessário conhecer quem faz uso do arquivo permanente para que os serviços de referência sejam planejados e executados com base no perfil e nas características destes usuários, visando atendê-los de forma satisfatória;

d) capacitação e orientação ao usuário quando ao uso dos instrumentos de referência, as políticas de acesso aos documentos e ao uso dos produtos e serviços do arquivo;

e) uso da internet e das tecnologias da informação para melhorar a acessibilidade e eficiência do serviço de referência;

f) adoção do processo de referência estruturado, com entrevista de referência, visando extrair informações necessárias do usuário para a localização da informação necessária; 
g) registro diário dos tipos de questões de referência apresentadas pelos usuários, que serve para embasar decisões quanto à criação de instrumentos de pesquisa específicos para atender demandas recorrentes e para preparar melhor o arquivista de referência para responder às questões apresentadas.

Com base nestas diretrizes, a implantação do serviço de referência em arquivos permanentes pode garantir o acesso à informação de maneira eficiente e amigável.

\section{REFERÊNCIAS}

ALMEIDA JÚNIOR, Oswaldo Francisco. Mediação da informação e múltiplas linguagens. In: ENANCIB, 9, 2008, São Paulo. Comunicação oral apresentada ao GT-03 - Mediação, Circulação e Uso da Informação Disponível em: <http://enancib.ibict.br/index.php/enancib/ixenancib/paper/ viewFile/3037/2163>. Acesso em: 6 nov. 2019

ARQUIVO NACIONAL (Brasil). Dicionário brasileiro de terminologia arquivística. Rio de Janeiro: Arquivo Nacional, 2005. 232 p.

BELLOTTO, Heloísa Liberalli. Arquivos permanentes: tratamento documental. 4. ed. Rio de Janeiro: Editora FGV, 2006. 320 p.

CONSELHO NACIONAL DE ARQUIVOS (BRASIL). Cursos de Arquivologia no Brasil. Disponível em: <http://conarq.arquivonacional.gov.br/linksuteis/389-cursos-de-arquivologia-no-brasil.html>. Acesso em: 1 nov. 2017.

GAMA, Fernando Alves; FERNEDA, Edberto. A mediação da informação nos arquivos permanentes: serviços de referência arquivística no ambiente digital. Inf. Inf., Londrina, v. 15, 1.2, p. 148-169, jul./dez. 2010

GROGAN, Denis. A prática do serviço de referência. Brasília, DF: Brinquet de Lemos, 2001. 195 p.

HERNÁNDES LUIS, José Luis. Reflexiones desde un servicio de referencia: propuestas para mejorar la atención al ciudadano em los archivos. Revista General de Información y Documentación. v. 26, n. 1, p. 103-118, 2016.

MENEZES, Priscila Lopes. O processo de difusão desenvolvido pelos arquivos públicos estaduais da região sul do Brasil. Ponto de Acesso, v. 6, n. 3, p. 47-71, dez. 2012.

NAVARRO BONILLA, Diego. El servicio de referencia archivístico: retos y oportunidades. Rev. Esp. Doc. Cient., v. 24, n. 2,p. 178-197, 2001.

PENTEADO, Pedro. Serviço de referência em arquivos definitivos: alguns aspectos teóricos. Cadernos BAD, n. 2, p. 19-41, 1995. 
RUTH, Janice E. Educating the reference archivist. American Archivist, v. 51, p. 266-276, Summer 1988.

SANTA ANNA, Jorge; CAMPOS, Suelen de Oliveira. Mediação da informação em arquivos: a necessidade de consolidação da prática do serviço de referência. Biblionline, João Pessoa, v. 12, n. 2, p. 68-83, 2016.

SCHELLENBERG, T. R. Arquivos modernos: princípios e técnicas. 6.ed. Rio de Janeiro, Editora FGV, 2006. 386 p

SILVA, Fabiano Couto Corrêa da. Bibliotecários especialistas: guia de especialidades e recursos informacionais. Brasília, DF: Thesauros, 2005.

TISSING, Robert W. The orientation interview in arquival research. American Arquivist, v. 47, n. 2, p. 173-178, Spring 1984.

UNIVERSIDADE ESTADUAL DA PARAÍBA. Currículo [do curso de Arquivologia]. Disponível em: <http://arquivologiauepb.com.br/curriculo/>. Acesso em: 1 nov. 2017.

UNIVERSIDADE ESTADUAL DE LONDRINA. Arquivologia: habilitação geral. Disponível em: <http://www.uel.br/prograd/catalogo-cursos/ Catalogo_2005/arquivologia.pdf>. Acesso em: 1 nov. 2017.

UNIVERSIDADE ESTADUAL PAULISTA. Estrutura curricular do curso [de Arquivologia]. Disponível em: <http://www.marilia.unesp.br/\#!/ graduacao/cursos/arquivologia/grade-curricular/estrutura-curricular-2012/>. Acesso em: 1 nov. 2017.

UNIVERSIDADE FEDERAL DA BAHIA. Matriz Curricular Diurno-Noturno [do curso de Arquivologia]. Disponível em: <https://blog.ufba.br/ici/files/ 2012/07/Matriz-Curricular-Diurno-Noturno-20101.pdf>. Acesso em: 1 nov. 2017.

UNIVERSIDADE FEDERAL DA PARAÍBA. Matriz curricular: Arquivologia. Disponível em: http://www.ccsa.ufpb.br/arqv/contents/menu/matriz-curricular Acesso em: 1 nov. 2017.

UNIVERSIDADE FEDERAL DE BRASÍLIA. Manual do curso de graduação em Arquivologia. Brasília, DF: UNB, 2017. 63 p. Disponível em: <http://webcache.googleusercontent.com/search?q=cache:J-vl8hgFn8o $\mathrm{J}$ :www.arquivologia.fci.unb.br/index.php/manual-do-curso/category/3manual-do-curso-de-arquivologia\%3Fdownload\%3D2:manual-do-curso-dearquivologia $+\& c d=1 \& \mathrm{hl}=\mathrm{pt}-B R \& \mathrm{ct}=\mathrm{clnk} \& \mathrm{gl}=\mathrm{br}>$. Acesso em: 1 nov. 2017.

UNIVERSIDADE FEDERAL DE MINAS GERAIS. Projeto Pedagógico do curso de Arquivologia. Belo Horizonte: UFMG, 2012. 180 p. Disponível em: $<$ http://colgradarquivo.eci.ufmg.br/documentos/projeto-pedagogico-do-cursode-arquivologia>. Acesso em: 1 nov. 2017.

UNIVERSIDADE FEDERAL DE SANTA MARIA. Portal do Ementário. Disponível em: <https://portal.ufsm.br/ementario/curso.html?idCurso=732>. Acesso em: 01 nov. 2017. 
UNIVERSIDADE FEDERAL DO AMAZONAS. Currículo de Curso:Arquivologia. Disponível em: <https://ecampus.ufam.edu.br/ecampus/ gradesCurriculares/report>. Acesso em: 1 nov. 2017.

UNIVERSIDADE FEDERAL DO ESPÍRITO SANTO. Estrutura do currículo.Disponível em: <http://arquivologia.ufes.br/sites/arquivologia.ufes. br/files/field/anexo/ppc_arquivologia_2016_versao_final_grade_curricular_e _ementario_26052017.pdf\#overlay-context=grade-curricular>. Acesso em: 1 nov. 2017

UNIVERSIDADE FEDERAL DO PARÁ. Grade de disciplinas [do curso de Arquivologia]. Disponível em: <https://drive.google.com/file/d/ OBwBxGTKKXMLjTmJpVTdIQnRiMXc/view>. Acesso em: 1 nov. 2017.

UNIVERSIDADE FEDERAL DO RIO GRANDE. Quadro de Sequência Lógica de disciplinas [do curso de Arquivologia]. Disponível em: <https://arquivologia.furg.br/disciplinas-obrigatorias>. Acesso em: 1 nov. 2017.

UNIVERSIDADE FEDERAL DO RIO GRANDE DO SUL. Arquivologia: Currículo: Grade curricular. Disponível em: <http://www.ufrgs.br/ufrgs/ensino/ graduacao/cursos/exibeCurso?cod_curso=301>. Acesso em: 1 nov. 2017.

UNIVERSIDE FEDERAL FLUMINENSE. [Grade Curricular do Curso de Arquivologia]. Disponivel em: <http://www.consultaesic.cgu.gov.br/busca/ dados/Lists/Pedido/Attachments/480761/RESPOSTA_PEDIDO_Matriz

Curricular2016_1465404972217.pdf>. Acesso em: 1 nov. 2017

UNIVERSIDADE FEDERAL DO ESTADO DO RIO DE JANEIRO. Quadro das disciplinas propostas pela reforma curricular - 2013 . Disponível em: <http://www.unirio.br/arquivologia/arquivos/Proposta\%20Matriz\%20Arquivologi a\%20versao\%202013\%20COMPLETA.pdf>. Acesso em: 1 nov. 2017.

VASCONCELOS, Kathyanne Samara Paulino; VERAS, Maria de Fátima Teixeira; SOUZA, Katia Isabelli de B. Melo de. Instituições e usuários dos arquivos: as formas de diálogo. In: SIMPÓSIO BAIANO DE ARQUIVOLOGIA, 3., 2011, Salvador, BA. Disponível em: <http://www.arquivistasbahia.org/3sba/wp-content/uploads/2011/09/

Vasconcelos-Veras-Souza.pdf>. Acesso em: 31 jul. 2017.

VAZ, Gláucia Aparecida; ARAÚJO, Carlos Alberto Ávila. A importância dos estudos de usuário na formação do arquivista. In: Encontro de Pesquisa em Informação e Mediação, 25. 2015, Marília, SP. Anais... São Paulo: UNESP, 2015.

Recebido em: 06/02/2019

Aceito em: 20/06/2019 